\title{
Improved Field Emission Characteristics of Large-Area Films of Molybdenum Trioxide Microbelt
}

\author{
Dongmei Ban, Shaozhi Deng, Ningsheng Xu, Jun Chen, Juncong She, and Fei Liu \\ State Key Lab of Optoelectronic Materials and Technologies, Guangdong Province Key Lab of Display Material and Technology, \\ School of Physics and Engineering, Sun Yat-sen University, Guangdong 510275, China \\ Correspondence should be addressed to Shaozhi Deng, stsdsz@mail.sysu.edu.cn
}

Received 15 September 2009; Revised 11 November 2009; Accepted 27 November 2009

Academic Editor: Yanqiu Zhu

Copyright ( 92010 Dongmei Ban et al. This is an open access article distributed under the Creative Commons Attribution License, which permits unrestricted use, distribution, and reproduction in any medium, provided the original work is properly cited.

We study the field emission characteristics of large-area films of crystalline $\mathrm{MoO}_{3}$ microbelt grown on silicon substrate by thermal evaporation in air using a commercial infrared sintering furnace. It is found that their turn-on field, threshold field, resistance to microdischarge and field emission current stability are better than $\mathrm{MoO}_{3}$ nanowires, $\mathrm{MoO}_{3}$ nanobelts and $\mathrm{MoO}_{3}$ nanoflower. In addition, good uniform distribution of field emission sites can be observed. The physical reasons are explained responsible for such improvements on field emission characteristics of $\mathrm{MoO}_{3}$ material. These results indicate that large-area $\mathrm{MoO}_{3}$ microbelts may be suitable for cold-cathode electron source application.

\section{Introduction}

Molybdenum trioxide, a wide-bandgap n-type semiconductor, has been studied as an interesting photochromic and electrochromic material with potential application in information display, sensor device, optoelectronic storage device, and smart window [1-12]. Recently, various forms of molybdenum trioxide nanostructure have been reported to exhibit attractive field characteristics, indicating their potential application as cold cathode electron emission material [13-16]. Molybdenum trioxide nanostructures can be produced under some conditions including solution method [17], hydrothermal method [13], and thermal evaporation [14-16]. The synthesis and the growth mechanism of $\mathrm{MoO}_{3}$ nanostructures have been investigated [13-21]. Recently, we developed an approach to prepare a large-area film of $\mathrm{MoO}_{3}$ nano/microstructures. With some degree of control, we were able to prepare large-area films of $\mathrm{MoO}_{3}$ microbelts in air and on ITO glasses or silicon substrates at low temperature without catalyst. In particular, the $\mathrm{MoO}_{3}$ microbelt films have been found to exhibit improved field emission characteristics as compared to those reported for various $\mathrm{MoO}_{3}$ nanostructures [13-16]. Here we report these findings and the possible physical reasons.

\section{Experimental}

Our sample preparation procedure is as below. ITO glasses or silicon substrates were washed with acetone and then with alcohol in an ultrasonic cleaner. The whole growth process was carried out in a commercial infrared sintering furnace, which comprises 6 temperature zones and their temperatures can be set to have a value in a range from room temperature to $1000^{\circ} \mathrm{C}$. In the present study, the temperature in different zones was set at $200^{\circ} \mathrm{C}, 200^{\circ} \mathrm{C}, 350^{\circ} \mathrm{C}, 700^{\circ} \mathrm{C}, 700^{\circ} \mathrm{C}$, and $100^{\circ} \mathrm{C}$, respectively. When the temperatures reached the set values, the substrates (size: $0.45 \mathrm{~cm} \times 0.5 \mathrm{~cm}$ ) and the quartz boat containing Mo powders were carried to the set zones by the transmission belt. With reference to Figure 1, the evaporation source was placed at the right-hand side of the $700^{\circ} \mathrm{C}$ zone and the three substrates were located at the positions with the separations between substrate and source of $27 \mathrm{~cm}, 32 \mathrm{~cm}$, and $37 \mathrm{~cm}$, respectively. In this arrangement, Sample 1 with separation $27 \mathrm{~cm}$ was in the $350^{\circ} \mathrm{C}$ zone, Sample 2 with separation of $32 \mathrm{~cm}$ in right hand side of the $350^{\circ} \mathrm{C}$ zone, and Sample 3 with separation of $37 \mathrm{~cm}$ in the $200^{\circ} \mathrm{C}$ zone. Thus, with reference to Figure 1, Samples 2 and 3 were in the regions where temperatures were below $350^{\circ} \mathrm{C}$. The growth time was 60 minutes. Finally, all 


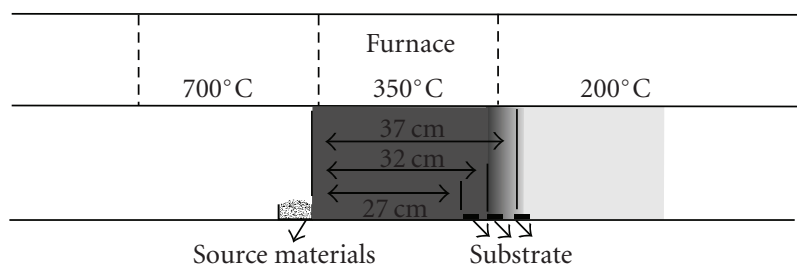

Figure 1: Schematic diagram showing how substrate and evaporation source are arranged inside the furnace.

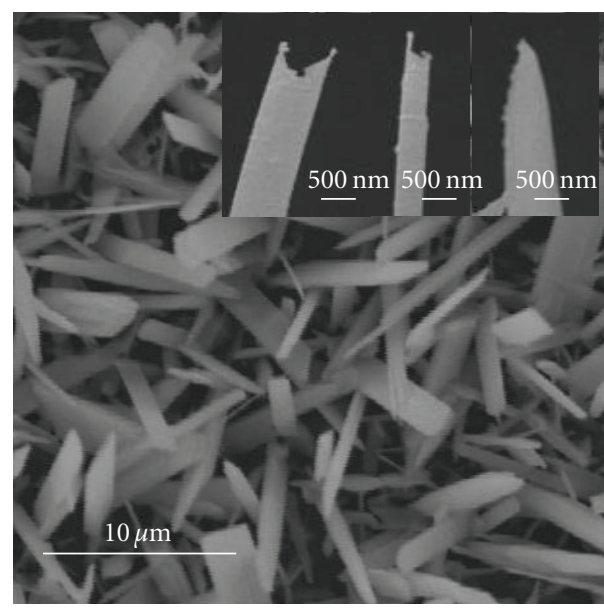

(a)

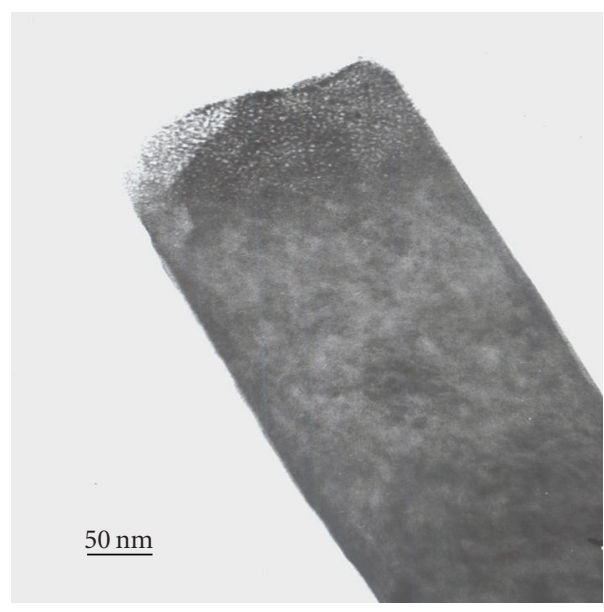

(c)

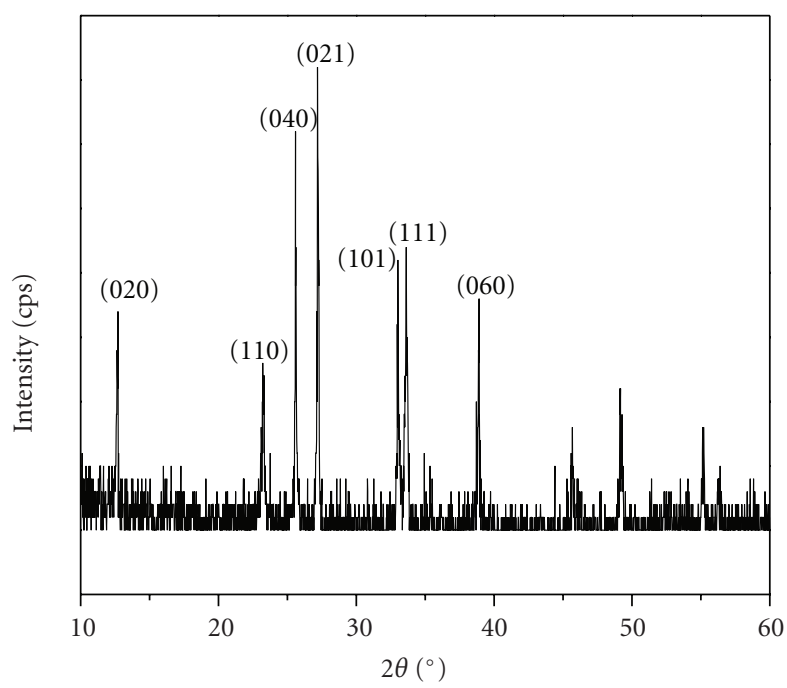

(b)

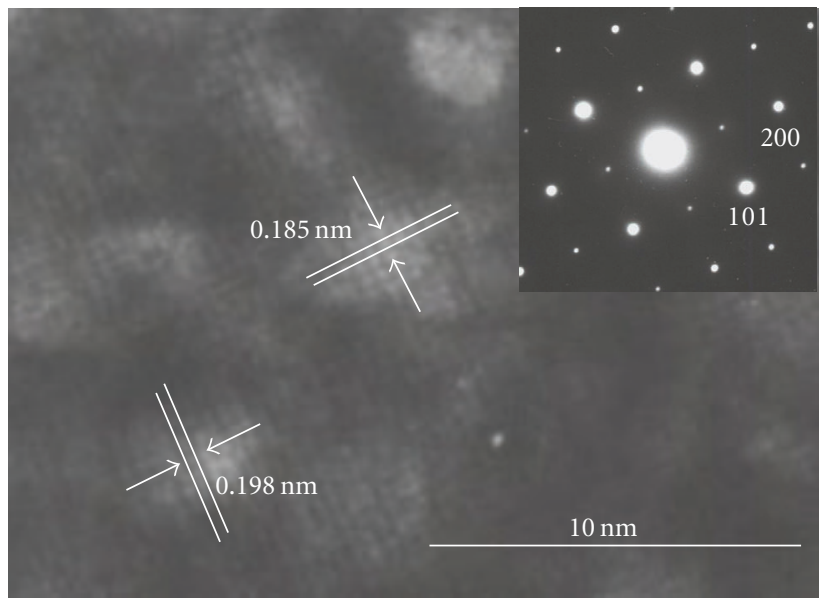

(d)

FIgURE 2: (a) The typical SEM image of the $\mathrm{MoO}_{3}$ microbelts, the insets showing high resolution SEM images. (b) XRD spectra of the MoO 3 microbelts. (c) TEM image and (d) HRTEM image of a $\mathrm{MoO}_{3}$ microbelt, the inset showing the corresponding SAED pattern.

the temperature zones were allowed to decrease gradually to room temperature. The substrates appeared white after deposition. The combination of the large area of each temperature zone $(35 \mathrm{~cm} \times 30 \mathrm{~cm})$ and uniformity in the temperature inside the zone may be very important to the development of a large-area film for device application.

\section{Results and Discussion}

The $\mathrm{MoO}_{3}$ microbelts were characterized by using Xray diffraction spectroscopy (D/max 2200 vpc apparatus with $\mathrm{Cu} \mathrm{K} \alpha$ radiation), scanning electron microscopy (SEM: Quanta 400F), and high-resolution transmission 


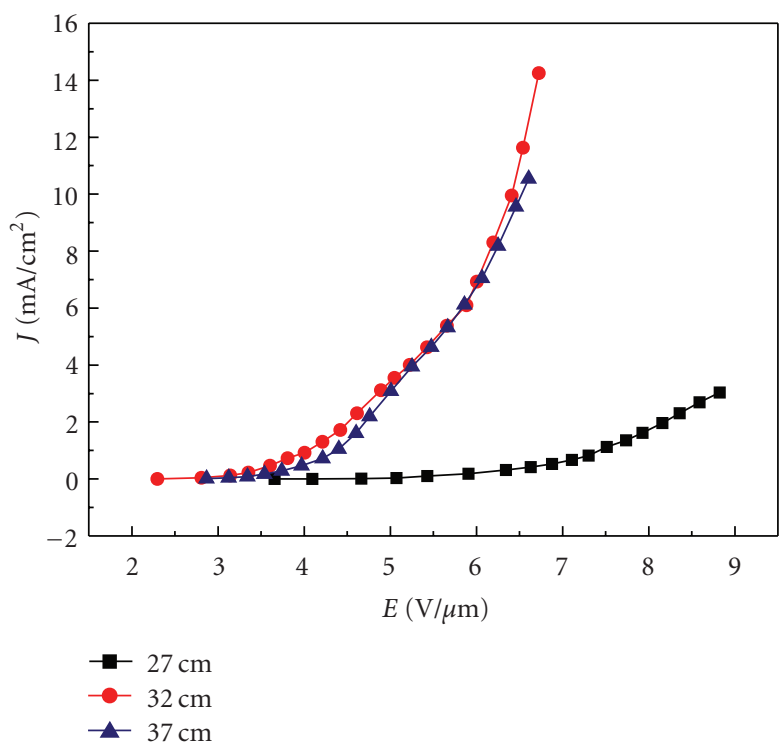

(a)

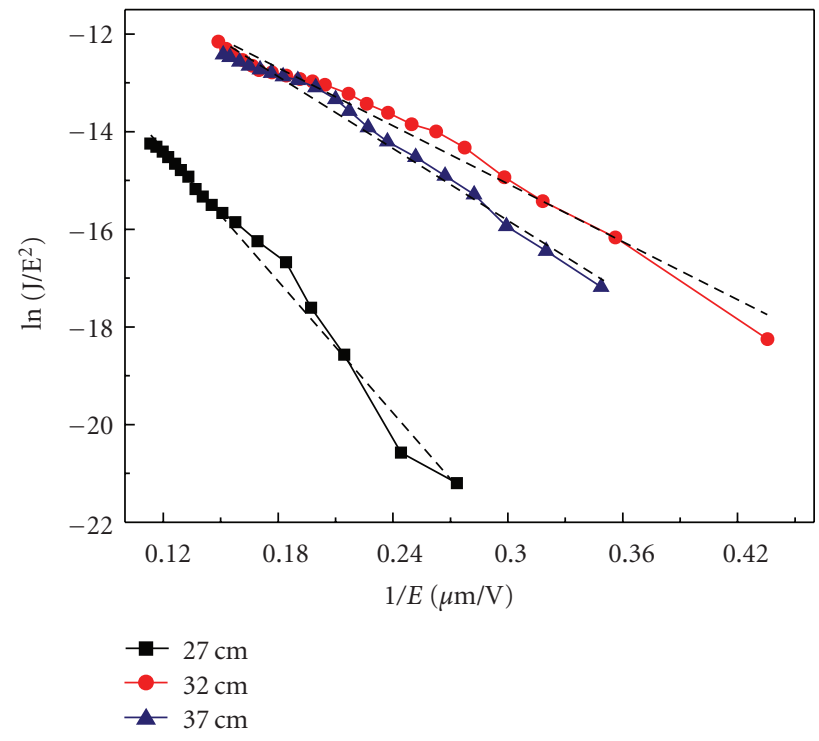

(b)

Figure 3: (a) The $J-E$ plots of the $\mathrm{MoO}_{3}$ microbelt films grown with different separations of substrate and evaporation source, (b) their corresponding F-N plots.

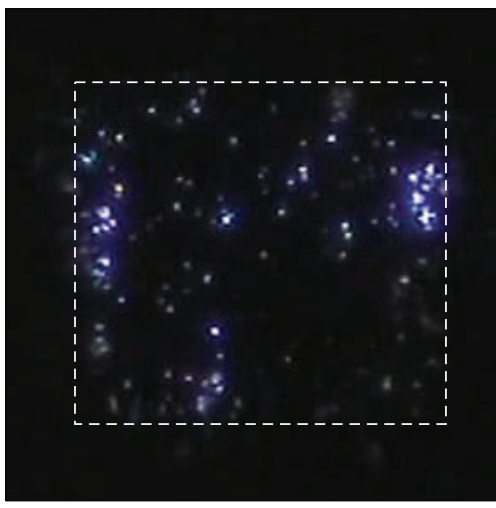

(a)

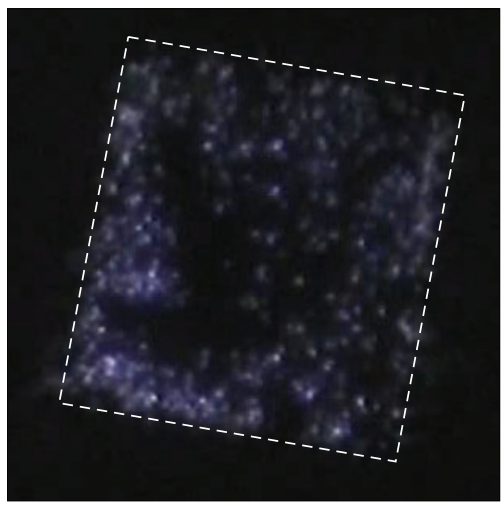

(b)

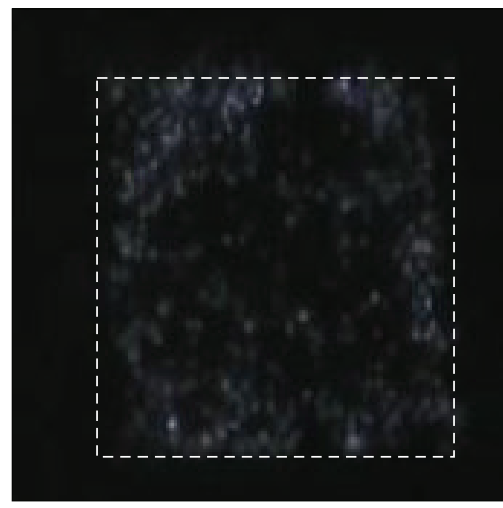

(c)

Figure 4: Optical images of the site distribution of the $\mathrm{MoO}_{3}$ microbelt films grown with different separation of substrate and evaporation source: (a) $27 \mathrm{~cm}$, (b) $32 \mathrm{~cm}$, and (c) $37 \mathrm{~cm}$ under similar gap fields: (a) $E=5.43 \mathrm{~V} / \mu \mathrm{m}$, (b) $E=5.43 \mathrm{~V} / \mu \mathrm{m},(\mathrm{c}) E=5.47 \mathrm{~V} / \mu \mathrm{m}$, the corresponding substrate areas are $0.45 \mathrm{~cm} \times 0.5 \mathrm{~cm}$, and $0.45 \mathrm{~cm} \times 0.5 \mathrm{~cm}$ and $0.45 \mathrm{~cm} \times 0.5 \mathrm{~cm}$, respectively. (The sample area is indicated by the dashed line.)

electron microscopy (HRTEM: JEM-2010HR). The SEM image (Figure 2(a)) shows that the average width of $\mathrm{MoO}_{3}$ microbelts is $\sim 1 \mu \mathrm{m}$ and their length is up to $10 \mu \mathrm{m}$. The microbelts are straight and their upper ends may be in the rectangular flat shape or have irregular one with sharp corners and nanotips as shown in the high resolution SEM images (insets of Figure 2(a)). The typical XRD pattern (Figure 2(b)) shows the diffraction peaks can be indexed to the orthorhombic structure $\mathrm{MoO}_{3}$ with the lattice constants $a=0.396 \mathrm{~nm}, b=1.386 \mathrm{~nm}, c=0.37 \mathrm{~nm}$ (JCPDS: 5 0508). Figure 2(c) is the low-magnification TEM image of the $\mathrm{MoO}_{3}$ microbelts. The high resolution TEM (HRTEM) image (Figure 2(d)) shows the two sets of parallel fringes with a spacing of $0.396 \mathrm{~nm}$ and $0.37 \mathrm{~nm}$ corresponding to the (100) and (001) planes, respectively. The SAED patterns (inset of Figure 2(d)) shows that the entire microbelt is single crystalline with a growth direction of [001].

The field emission measurements of microbelts were carried out in a vacuum chamber of $\sim 5.0 \times 10^{-7}$ torr at room temperature. The substrate with microbelts was first adhered to the surface of an oxygen-free, high-conductivity copper disc. A transparent anode, consisting of a quartz plate $4 \mathrm{~cm}$ in diameter and coated with conducting indium doped tin oxide film, was placed in front of, and parallel to, the surface of the sample cathode. First, we investigated how the field emission characteristics of the $\mathrm{MoO}_{3}$ microbelt film may be affected by the arrangement of substrate and evaporation source. Figure 3 shows $J-E$ characteristics and 


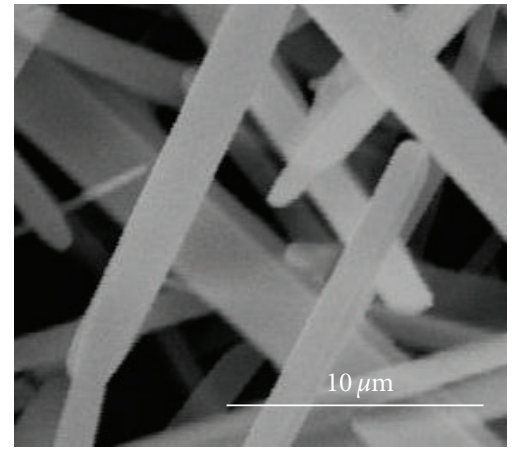

(a)

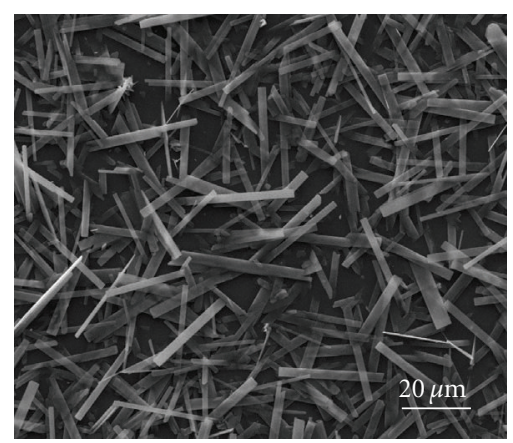

(d)

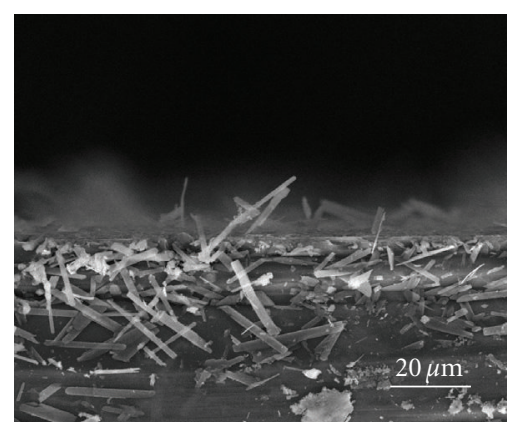

(g)

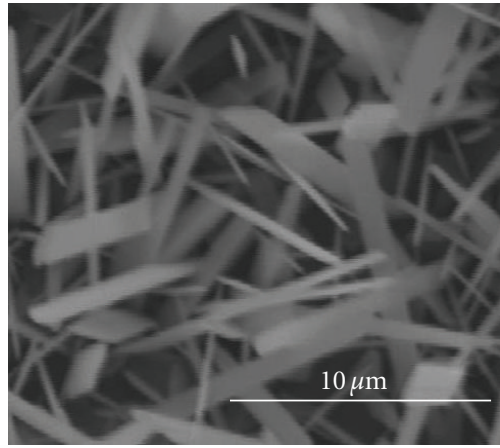

(b)

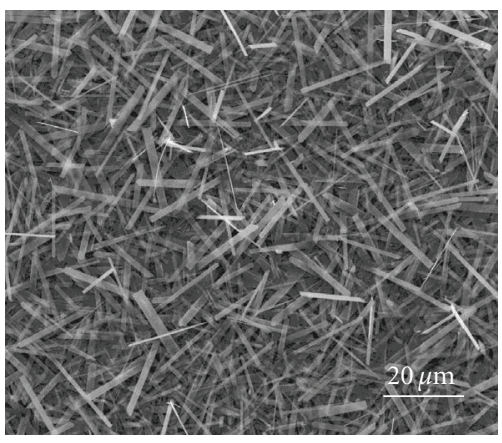

(e)

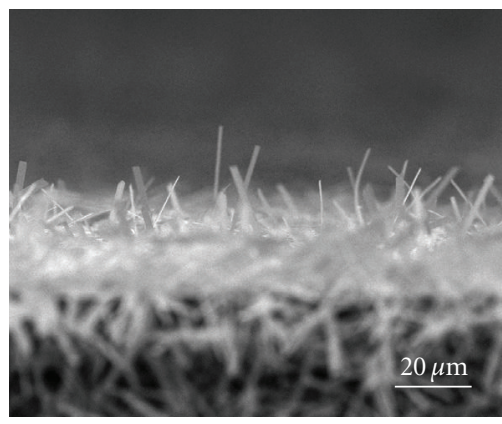

(h)

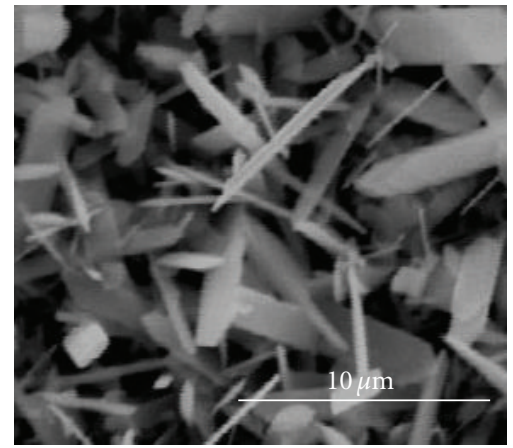

(c)

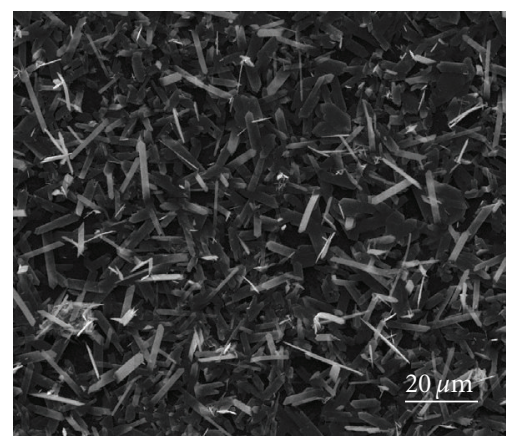

(f)

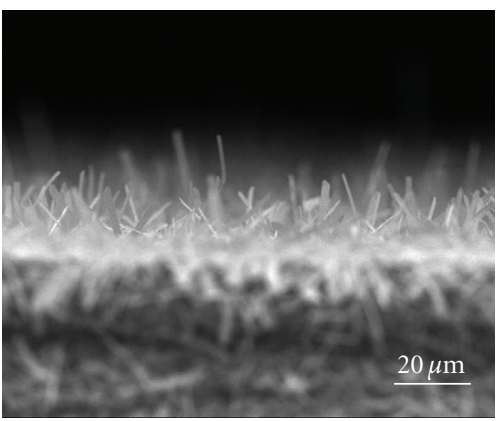

(i)

FIgURE 5: The typical SEM images (top view) of the $\mathrm{MoO}_{3}$ microbelts with different separations between substrate and evaporation: (a), (d) $27 \mathrm{~cm}$, (b) (e) $32 \mathrm{~cm}$, (c), (f) $37 \mathrm{~cm}$, the corresponding cross-section SEM images are in (g), (h) and (i), respectively.

the corresponding F-N plots of the three samples. Sample 1 has poor emission performance and Samples 2 and 3 show attractive characteristics. The turn-on fields (required to obtain field emission current of $10 \mu \mathrm{A} / \mathrm{cm}^{2}$ ) of Sample 1,2 , and 3 are $4.6,2.6$, and $3.0 \mathrm{~V} / \mu \mathrm{m}$, respectively, and the threshold fields (required to obtain field emission current of $10 \mathrm{~mA} / \mathrm{cm}^{2}$ ) of Samples 2 and 3 are 6.4 and $6.5 \mathrm{~V} / \mu \mathrm{m}$, respectively. Compared to the reports earlier, the best turnon field of the film of $\mathrm{MoO}_{3}$ microbelts $(2.6 \mathrm{~V} / \mu \mathrm{m})$ is lower than that of the $\mathrm{MoO}_{3}$ nanowires $(3.5 \mathrm{~V} / \mu \mathrm{m})[14,15]$, nanobelt $(8.7 \mathrm{~V} / \mu \mathrm{m})$ [16], and nanoflower $(4.3 \mathrm{~V} / \mu \mathrm{m})$ [13]. This result indicates that the $\mathrm{MoO}_{3}$ microbelt is a good candidate as cold-cathode material. The good field emission properties of the samples may be attributed to a number of factors, and the first may be the field enhancement effect. The values of field enhancement factor $\beta$ of the microbelt samples were calculated by using the F-N formulation [22]

$$
S_{\mathrm{FN}}=\frac{d\left(\ln \left(J / E^{2}\right)\right)}{d(1 / E)}=-\frac{6.53 \times 10^{9} \phi^{3 / 2}}{\beta},
$$

where $\phi$ is the work function of the molybdenum trioxide, $S_{\mathrm{FN}}$ is the slope of the F-N plot. The value of the $\beta$ factor may be derived by using the above expression provided that $\phi$ is constant. In the calculation, the work function of $\mathrm{MoO}_{3}$, $\phi=5.4 \mathrm{eV}$ [23], is used. From the F-N plots, we obtain that the values of field enhancement factor $\beta$ for Samples 1,2 , and 3 are 1822, 4165 and 3861, respectively. The $\beta$ value of Sample 1 is much smaller than that of the other two samples. Figure 4 shows the optical images of emission 


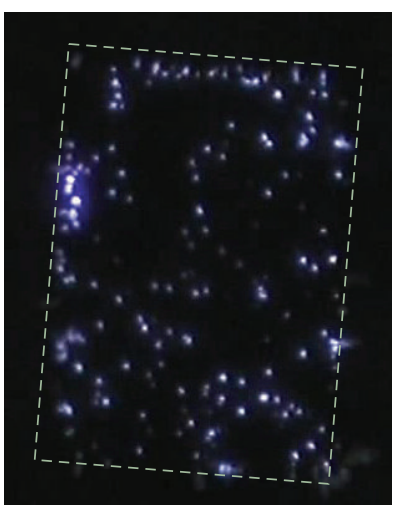

(a)

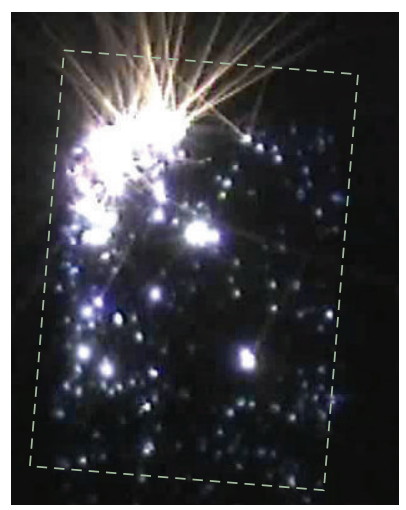

(b)

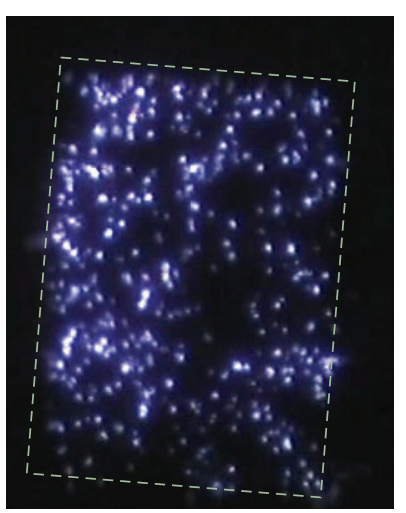

(c)

FIgURE 6: The optical images of the site distribution of the $\mathrm{MoO}_{3}$ microbelts film $(0.5 \mathrm{~cm} \times 0.7 \mathrm{~cm})$ taken under different gap fields: (a) $E=5.38 \mathrm{~V} / \mu \mathrm{m},(\mathrm{b}) E=5.55 \mathrm{~V} / \mu \mathrm{m}$, (c) $E=5.82 \mathrm{~V} / \mu \mathrm{m}$. (The sample area is indicated by the dashed line.)

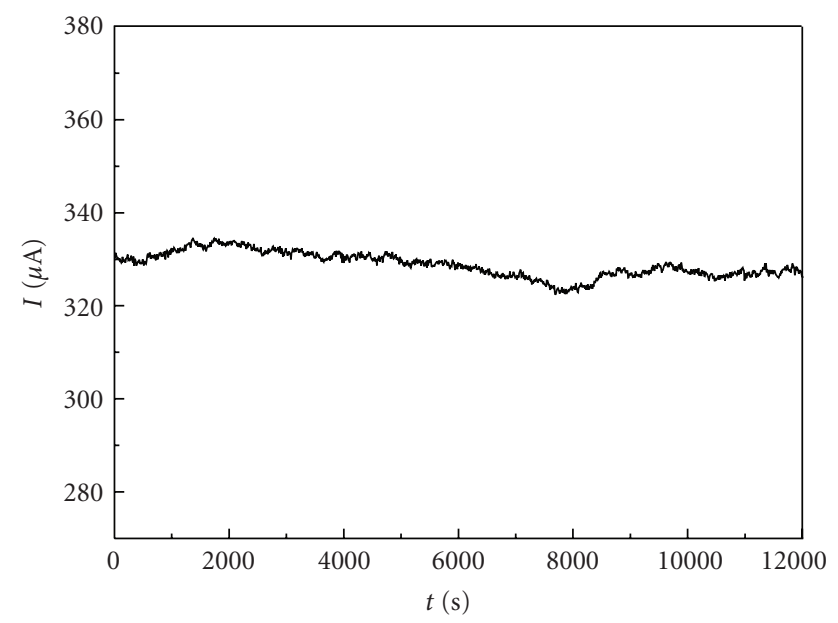

Figure 7: The curve of field emission current versus time, showing good stability of field emission of the $\mathrm{MoO}_{3}$ microbelt film.

site distribution recorded using transparent anode, and it is found that the emission sites of Samples 2 and 3 are distributed over the entire sample surface, while for Sample 1 the number of emission sites and their intensity are relatively low. These differences and similarity may be explained by the observed morphology features of the samples as seen under scanning electron microscope. The top-down SEM images (Figures 5(a) to 5(f)) show that the averaged length of the $\mathrm{MoO}_{3}$ microbelts of Sample 1 (Figures 5(a) and 5(d)) is longest compared to that of the other two samples (Figures 5(b), 5(c), 5(e) and 5(f)), but the corresponding crosssection image (Figure 5(g)) shows that it grows leaning to the substrate, which is not useful to the field enhancement. On contrary, the orientation of the $\mathrm{MoO}_{3}$ microbelts of Samples 2 and 3 (Figures $5(\mathrm{~h})$ and $5(\mathrm{i})$ ) is almost vertical to the substrate surface; this can enhance the field at the top ends of these vertically aligned microbelts, and thus strong emission from the apexes of these microbelts may be expected. Thus, these two samples have large $\beta$-values. This observation is in consistence with earlier findings that have revealed that vertically aligned nanowires have better field emission properties because of higher field enhancement at the end of each nanowire $[14,24]$.

As to the difference between the orientations of the microbelts of Sample 1 and Samples 2 and 3, a brief explanation is given below. Because of thermal radiation, the closer the substrate to the evaporation source is, the higher temperature the substrate is. When the temperature of the substrate is higher, the nucleation for microbelt growth is more difficult in comparison with a lower temperature one. Thus, the density of microbelts is lower for high temperature substrate, and when is too low, microbelts cannot support each other, so they cannot grow vertically to the substrate surface. This can explain why microbelts of Sample 1 grew leaning to the substrate, which was placed at the position less than $27 \mathrm{~cm}$ to the source, and was much closer to the source compared to Samples 2 and 3.

Additionally, we should like to explain why the calculated $\beta$-values are so large. We believe that this is not all contributed by the geometrical field enhancement. Other factors may be responsible to this, such as reduction in surface potential barrier for field emission or hot electron emission [22]. These are highly possible for field emission from semiconductors such as $\mathrm{MoO}_{3}$. If these are the cases, we may have to replace the value of $\phi$ with a more realistic value that reflects the lowering of the surface potential barrier in the calculation using the F-N formulation. This reduction in the value of $\phi$ can significantly decrease the $\beta$-value. But all these have to be confirmed by further experiments.

Second, using samples grown under the similar conditions described above with separation $32 \mathrm{~cm}$, we found that the films of $\mathrm{MoO}_{3}$ microbelts are resistant to the effects of local microdischarge event. Figure 6 shows three optical images of emission site distributions of one sample taken under three gap field conditions. One may see that after the local microdischarge events (Figure 6(b)), the emission sites distribution was not obviously changed, by comparing Figures 6(a) and 6(c).

Finally, we observed stable emission of the films over 3 hours time duration. The typical field emission $I-t$ curve is 
shown in Figure 7. No significant decrease of current was observed and the fluctuation is about $2 \%$ at a constant electric field of $4.47 \mathrm{~V} / \mu \mathrm{m}$ for an average emission current of $330 \mu \mathrm{A}$.

\section{Conclusion}

In summary, we have demonstrated that large-area films of crystalline $\mathrm{MoO}_{3}$ microbelts may be grown on ITO glasses or silicon substrates by thermal evaporation in air using a commercial infrared sintering furnace. Their typical turn-on field as low as $2.6 \mathrm{~V} / \mu \mathrm{m}$ and threshold field of $6.4 \mathrm{~V} / \mu \mathrm{m}$ are superior to the values reported for $\mathrm{MoO}_{3}$ nanostructures. Their field emission performance may be affected by the orientation of the $\mathrm{MoO}_{3}$ microbelts; the microbelts vertical to the substrate have a better field emission property. In addition, the good uniform distribution of emission sites on large-area samples is also observed. Finally, the $\mathrm{MoO}_{3}$ microbelts show good field emission current stability over time.

\section{Acknowledgment}

The authors gratefully acknowledge the financial support of the project from the National Natural Science Foundation of China (Grant nos. U0634002, 50725206, 60571035, and 50672135), Science and Technology Ministry of China (National Basic Research Program of China: Grant nos. 2003 CB314701, 2007CB935501 and 2008AA03A314), the Science and Technology Department of Guangdong Province, the Department of Information Industry of Guangdong Province, and the Science and Technology Department of Guangzhou City.

\section{References}

[1] E. Comini, L. Yubao, Y. Brando, and G. Sberveglieri, "Gas sensing properties of $\mathrm{MoO}_{3}$ nanorods to $\mathrm{CO}$ and $\mathrm{CH}_{3} \mathrm{OH}$," Chemical Physics Letters, vol. 407, no. 4-6, pp. 368-371, 2005.

[2] A. M. Taurino, A. Forleo, L. Francioso, P. Siciliano, M. Stalder, and R. Nesper, "Synthesis, electrical characterization, and gas sensing properties of molybdenum oxide nanorods," Applied Physics Letters, vol. 88, no. 15, Article ID 152111, 3 pages, 2006.

[3] Z. Hussain, "Optical and electrochromic properties of heated and annealed $\mathrm{MoO}_{3}$ thin films," Journal of Materials Research, vol. 16, no. 9, pp. 2695-2708, 2001.

[4] H. C. Zeng, "Chemical etching of molybdenum trioxide: a new tailor-made synthesis of $\mathrm{MoO}_{3}$ catalysts," Inorganic Chemistry, vol. 37, no. 8, pp. 1967-1973, 1998.

[5] J. N. Yao, K. Hashimoto, and A. Fujishima, "Photochromism induced in an electrolytically pretreated $\mathrm{MoO}_{3}$ thin film by visible light," Nature, vol. 355, no. 6361, pp. 624-626, 1992.

[6] J. N. Yao, Y. A. Yang, and B. H. Loo, "Enhancement of photochromism and electrochromism in $\mathrm{MoO}_{3} / \mathrm{Au}$ and $\mathrm{MoO}_{3} / \mathrm{Pt}$ thin films," Journal of Physical Chemistry B, vol. 102, no. 11, pp. 1856-1860, 1998.

[7] Y. A. Yang, Y. W. Cao, B. H. Loo, and J. N. Yao, "Microstructures of electrochromic $\mathrm{MoO}_{3}$ thin films colored by injection of different cations," Journal of Physical Chemistry B, vol. 102, no. 47, pp. 9392-9396, 1998.

[8] K. Shao, Y. Ma, Y. A. Cao, Z. H. Chen, X. H. Ji, and J. N. Yao, "Inclusion of poly(tetramethyl-p-phenyl-enediamine dihydrochloride) into $\mathrm{MoO}_{3}$ : a cooperative formation route to construct a polymer/ $\mathrm{MoO}_{3}$ layered structure," Chemistry of Materials, vol. 13, no. 2, pp. 250-252, 2001.

[9] P. Pichat, M. N. Mozzanega, and C. Hoang-Van, "Room temperature photoassisted formation of hydrogen-molybdenum bronzes with an alcohol as a hydrogen source," Journal of Physical Chemistry, vol. 92, no. 2, pp. 467-470, 1988.

[10] C. Bechinger, S. Ferrere, A. Zaban, J. Sprague, and B. A. Gregg, "Photoelectrochromic windows and displays," Nature, vol. 383, no. 6601, pp. 608-610, 1996.

[11] G. Laperrière, M. A. Lavoie, and D. Bélanger, "Electrochromic behavior of molybdenum trioxide thin films, prepared by thermal oxidation of electrodeposited molybdenum trisulfide, in mixtures of nonaqueous and aqueous electrolytes," Journal of the Electrochemical Society, vol. 143, no. 10, pp. 3109-3117, 1996.

[12] T. Maruyama and T. Kanagawa, "Electrochromic properties of molybdenum trioxide thin films prepared by chemical vapor deposition," Journal of the Electrochemical Society, vol. 142, no. 5, pp. 1644-1647, 1995.

[13] G. Wei, W. Qin, D. Zhang, et al., "Synthesis and field emission of $\mathrm{MoO}_{3}$ nanoflowers by a microwave hydrothermal route," Journal of Alloys and Compounds, vol. 481, no. 1-2, pp. 417421, 2009.

[14] J. Zhou, S. Z. Deng, N. S. Xu, J. Chen, and J. C. She, "Synthesis and field-emission properties of aligned $\mathrm{MoO}_{3}$ nanowires," Applied Physics Letters, vol. 83, no. 13, pp. 2653-2655, 2003.

[15] J. Zhou, N. S. Xu, S. Z. Deng, J. Chen, J. C. She, and Z. L. Wang, "Large-area nanowire arrays of molybdenum and molybdenum oxides: synthesis and field emission properties," Advanced Materials, vol. 15, no. 21, pp. 1835-1840, 2003.

[16] Y. B. Li, Y. Bando, D. Golberg, and K. Kurashima, "Field emission from $\mathrm{MoO}_{3}$ nanobelts," Applied Physics Letters, vol. 81, no. 26, pp. 5048-5050, 2002.

[17] X. L. Li, J. F. Liu, and Y. D. Li, "Low-temperature synthesis of large-scale single-crystal molybdenum trioxide $\left(\mathrm{MoO}_{3}\right)$ nanobelts," Applied Physics Letters, vol. 81, no. 25, pp. 48324834, 2002.

[18] L. Jiao, H. Yuan, Y. Si, Y. Wang, M. Zhao, and Y. Wang, "A novel method for synthesis of microstructure $\mathrm{MoO}_{3}$," Materials Letters, vol. 59, no. 24-25, pp. 3112-3114, 2005.

[19] G. Li, L. Jiang, S. Pang, H. Peng, and Z. Zhang, "Molybdenum trioxide nanostructures: the evolution from helical nanosheets to crosslike nanoflowers to nanobelts," Journal of Physical Chemistry B, vol. 110, no. 48, pp. 24472-24475, 2006.

[20] G. Wang, Y. Ji, L. Zhang, Y. Zhu, P. I. Gouma, and M. Dudley, "Synthesis of molybdenum oxide nanoplatelets during crystallization of the precursor gel from its hybrid nanocomposites," Chemistry of Materials, vol. 19, no. 5, pp. 979-981, 2007.

[21] I. Navas, R. vinodkumar, K. J. Lethy, et al., "Growth and characterization of molybdenum oxide nanorods by RF magnetron sputtering and subsequent annealing," Journal of Physics D, vol. 42, no. 17, Article ID 175305, 8 pages, 2009.

[22] N. S. Xu, High Voltage Vacuum Insulator: Basic Concepts and Technological Practice, edited by R. V. Latham, chapter 4, Academic, London, UK, 1995.

[23] J. Cao, X. Jiang, and Z. Zhang, " $\mathrm{MoO}_{x}$ modified Ag anode for top-emitting organic light-emitting devices," Applied Physics Letters, vol. 89, no. 25, Article ID 252108, 3 pages, 2006.

[24] Q. B. Wu, S. Ren, S. Z. Deng, J. Chen, and N. S. Xu, "Growth of aligned $\mathrm{Cu}_{2} \mathrm{~S}$ nanowire arrays with AAO template and their field-emission properties," Journal of Vacuum Science and Technology B, vol. 22, no. 3, pp. 1282-1285, 2004. 

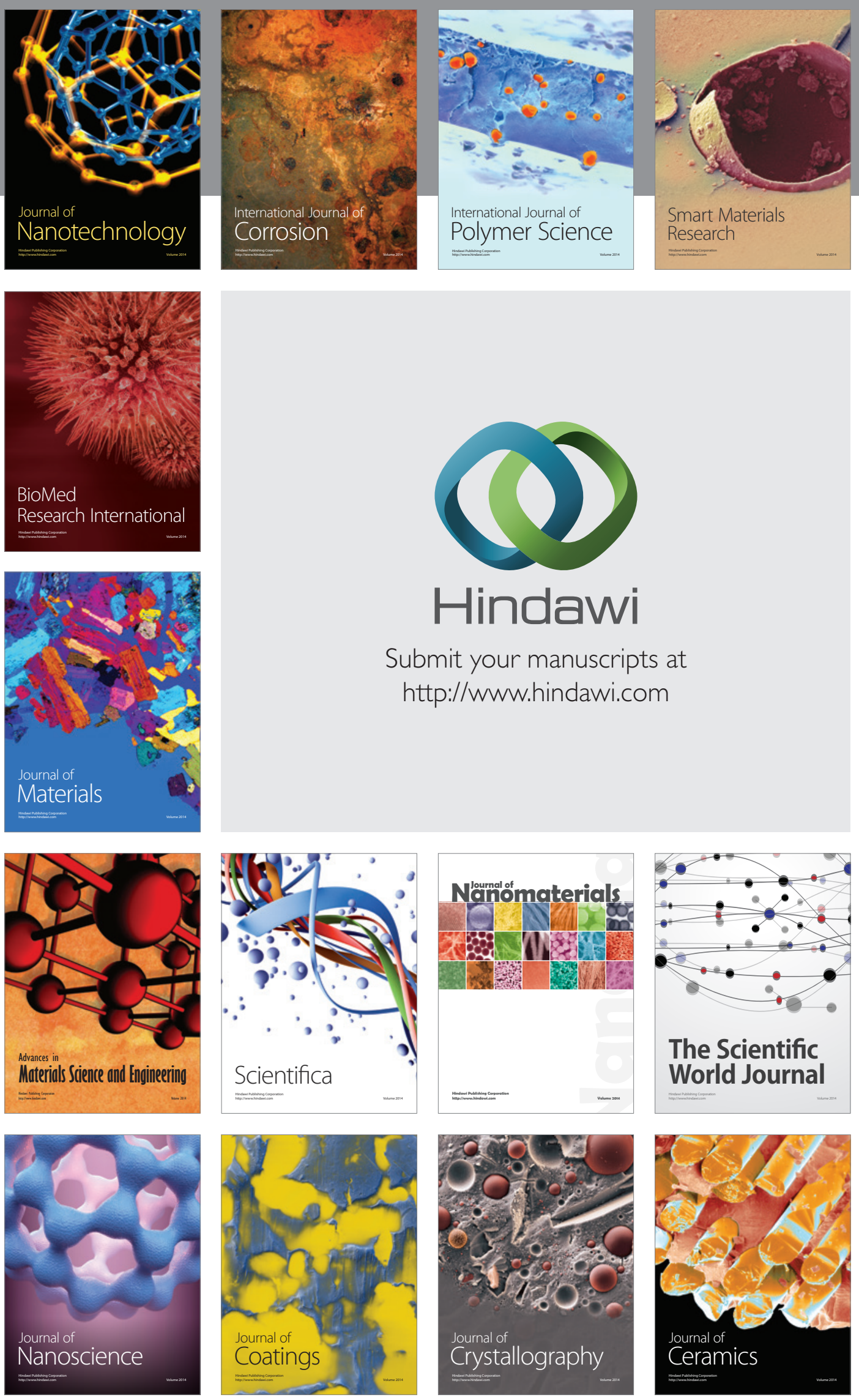

The Scientific World Journal

Submit your manuscripts at

http://www.hindawi.com

\section{World Journal}

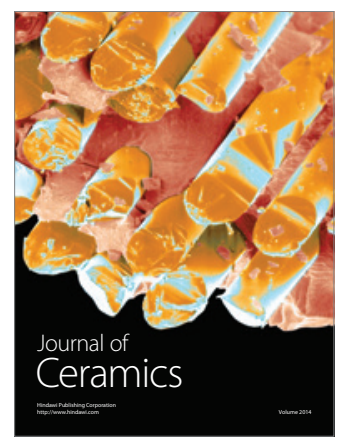

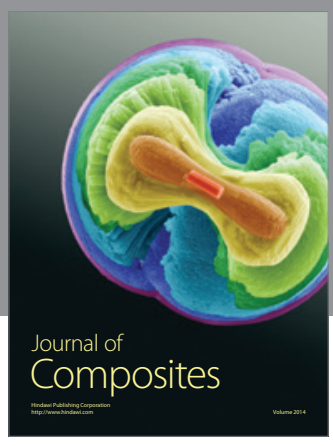
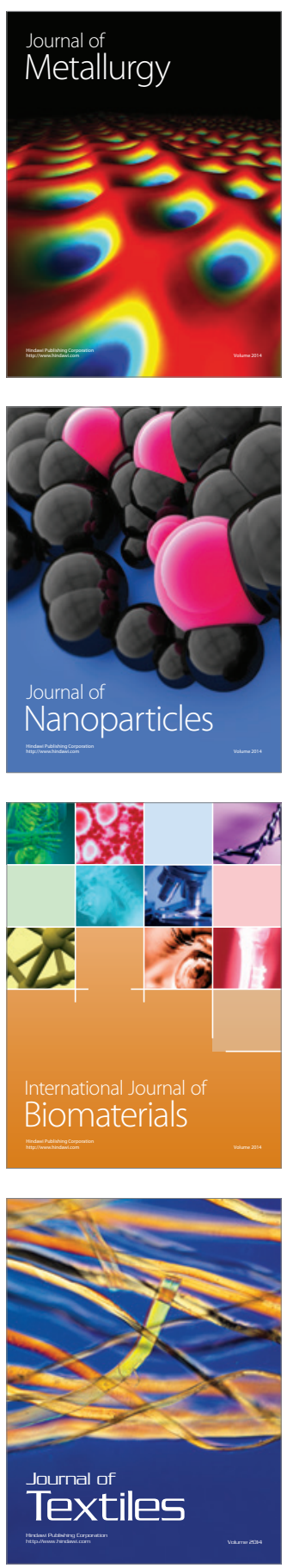